\title{
NUMERICAL ANALYSIS ON THE INFLUENCE OF INFLOW GUIDE VANES IN A SOLAR VORTEX POWER GENERATOR
}

\author{
ALI ISMAEEL ${ }^{1,2}$, HUSSAIN AL-KAYIEM $^{1}$, AKLILU BAHETA $^{1} \&$ MOHAMMED AURYBI $^{1}$ \\ ${ }^{1}$ Mechanical Engineering Department, Universiti Teknologi PETRONAS, 32610 Bandar Seri Iskandar, Malaysia \\ ${ }^{2}$ Department of Electromechanical Engineering, University of Technology, Baghdad, Iraq
}

\begin{abstract}
A preliminary experimental model of solar vortex power generation (SVPG) has been built for the evaluation of the newly introduced system. It experienced set back in the design of the inflow guiding arrangement. This paper presents a numerical simulation of swirl air generator as part of the proposed SVPG. ANSYS FLUENT software has been used to solve Navier-Stokes and energy equations in cylindrical coordinates system integrated with discrete ordinates radiation model. The configuration of the swirl air generator was modelled and simulated with eight air inflow. Each air inflow comprised of the open slot for air flow and guide vane. Two different heights, $0.3 \mathrm{~m}$ and $0.6 \mathrm{~m}$ of the air entry have been simulated. The Computational fluid dynamics (CFD) simulation procedure has been validated with the help of results that were acquired through the measurements carried out utilizing the experimental model constructed in the solar research site (SRS) at the Universiti Teknologi PETRONAS, Malaysia. The computational results show that by increasing the height of guide vanes and the inflow slots the swirling strength enhanced by $50 \%$. The mass flow rate under the same operational solar and weather conditions was improved by $50 \%$. Thereby, a decision has been made to modify the existing system based on the present CFD simulation results.
\end{abstract}

Keywords: renewable energy, solar energy, solar thermal, solar updraft, swirl generator.

\section{INTRODUCTION}

The concept of harvesting energy from the extreme atmosphere such as dust devils and tornado phenomena, to produce a clean electric power as a new renewable energy source was evaluated by the researchers in previous studies [1], [2]. This concept depends on a technique of generating the artificial updraft hot air like the vortex, which converts thermal energy into mechanical work during an upward heat convection motion of the air, in the same way as the heat engine works [3], [4]. To build up the updraft vortex stream [5], [6]. A heat source utilizing to upgrade the buoyancy forces of the hot air, such as the Solar Vortex Engine (SVE) was proposed by AI-Kayiem and Mustafa [7], as shown in Fig. 1.

The SVE comprises of two main parts, solar air collector (SAC) and Vortex generation engine (VGE). The SVE has been developed by utilizing a new design for the guide vanes or deflectors inside the VGE by using curvature deflectors to smooth and enhance the vortex generated by the engine [2]. For power generation, the axial flow turbine is located immediately upstream of the air flow leaving the solar air collector at the base of the SVE. The air flow through the turbine is then directed to flow through a narrow passage and the core of the engine through deflectors imposing rotational motion. Then, the air flows up through a small opening in the upper cover of the core and moves up to the open atmosphere in swirling motion, like a vortex [2]. Although the SVE is a low-cost and simple configuration but the stack effect inside the vortex generator is weak without the heat source to generate the initial vortex and maintain the updraft continuously. 


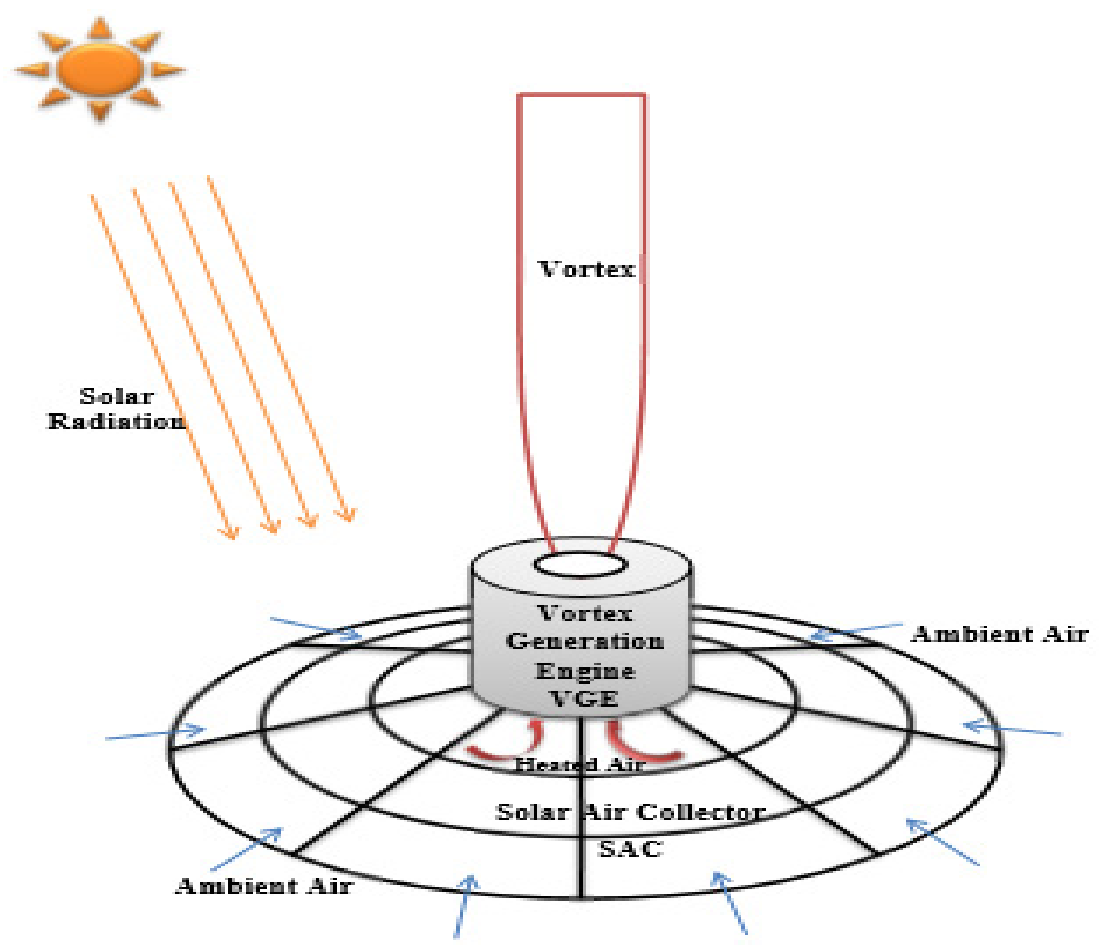

Figure 1: SVE [8].

Therefore, the enhancement and development of the concept of solar vortex updraft for power generation was studied in the Solar Research Site (SRS) at the Universiti Teknologi PETRONAS - Malaysia. Hence, a new model of a swirl air generator (SAG) integrated with two solar collectors has been created, named as Solar Vortex Power Generator (SVPG). The objective of this study simulated the impact of inflow guide vanes dimension on the swirling strength by using a computational fluid dynamics (CFD) to evaluate the optimum design of the SAG part for the SVPG future work development.

\section{PRELIMINARY DESIGN OF SVPG}

There are three main parts of SVPG, as shown in Fig. 2. Through a series of energy conversion processes, the greenhouse effect by the solar collector (SC) part transforms the solar radiation into the air stream which helps to avoid the environmental wind effect by confirming a control. This results in the movement of hot air towards the Swirl air generator (SAG) part.

There is an upper cover (UC) over the upper solar collector part, having Transparent Structure (TS), that is employed as a source to create the initial convective vortex. There are two functions of UC, firstly, to trap the solar energy for the heating of the air present in the SAG, secondly, to create the updraft flow during the process of withdrawing hot air from the SC part to the SAG. Rotational swirling motion, similar to vortex, inside the SAG was created by accelerating the air flow through guide vanes. In the path of vortex-induced flow, vertical wind turbine with electrical generator can be placed to produce electricity. Vertical wind turbine with electrical generator extracts kinetic energy and produces power. 


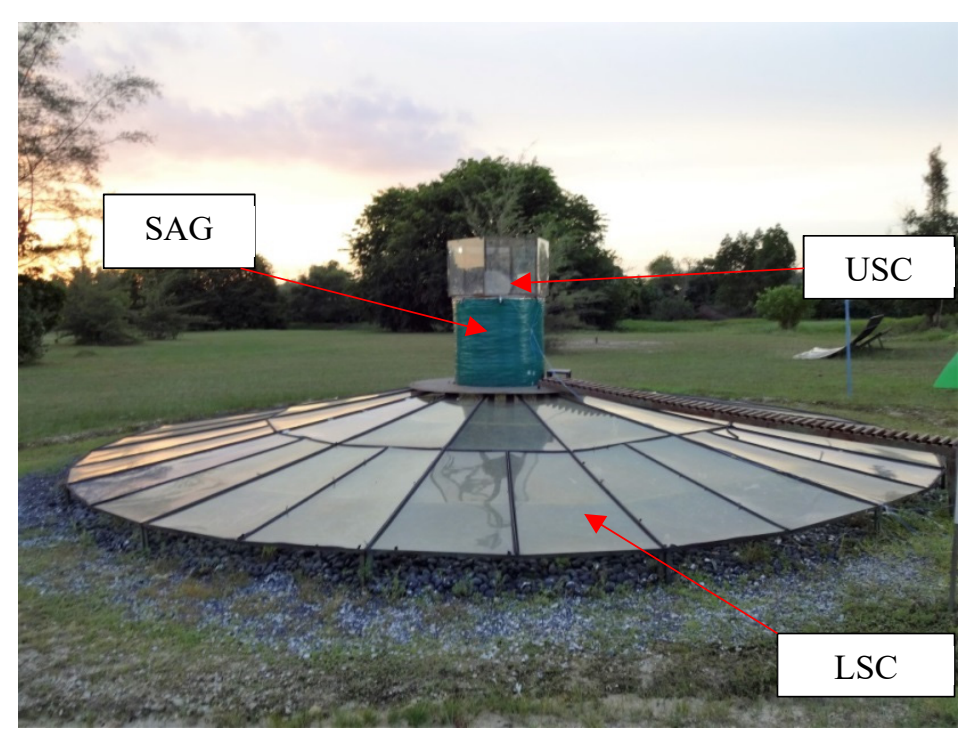

Figure 2: SVPG.

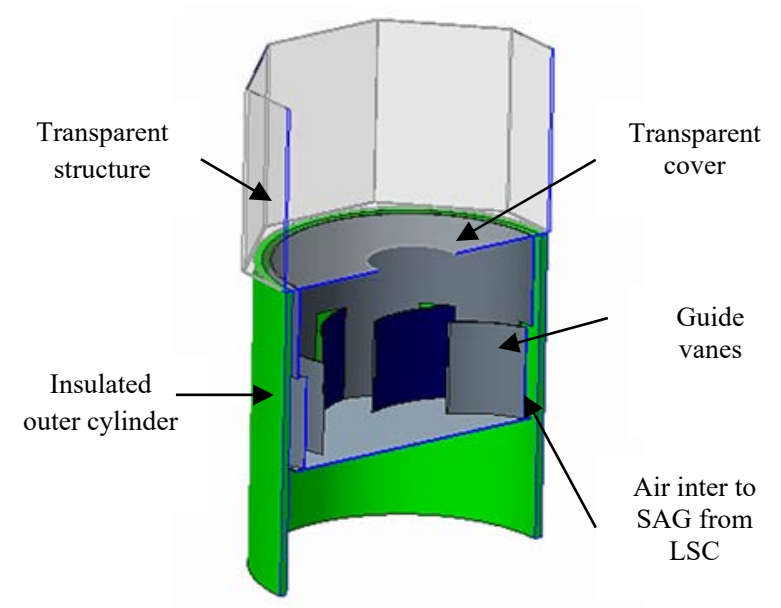

Figure 3: Preliminary model of SAG \& USC configuration.

\section{NUMERICAL SIMULATIONS}

\subsection{Preliminary model of SAG and USC configuration}

A 3-D geometrical modelling for the SAG and USC based on the prototype model was supported with a pre-processing tool - GAMBIT 2.4.6. The geometry was transferred to ANSYS Fluent software (15) for further meshing and simulation [9]. 
The dimensions of the SAG were: the diameter of the inner cylinder was $0.9 \mathrm{~m}$ with a height of $0.6 \mathrm{~m}$, the outer cylinder was of diameter $1 \mathrm{~m}$ with the height of $0.6 \mathrm{~m}$, the guide vanes were set to $25^{\circ}$ with a height of $0.3 \mathrm{~m}$ and length of $0.35 \mathrm{~m}$. The entry slot width was $0.1 \mathrm{~m}$ with the height of $0.3 \mathrm{~m}$. On the other hand, the USC comprised of upper cover (UC) with Transparent Structure (TS), The TS was $0.6 \mathrm{~m}$ in height having a polygon shape. The diameter of the UC was $0.1 \mathrm{~m}$ with the hole of $0.3 \mathrm{~m}$ in diameter at its centre used for vortex updraft flow exit.

\subsection{Numerical simulation methods}

Simulation of a Fluent employed Boussinesq Model for natural convection [10]. In all solved equations, density was assumed to be constant in this model, apart from the buoyancy term in the momentum equation. Simulations were conducted based on $k-\varepsilon$ turbulence model with RNG. The Semi Implicit Method for Pressure Linked Equation - Consistent (SIMPLEC) algorithm was applied for second order discretization of pressure; momentum and energy obtained more converged solution. Discrete Ordinates (DO) have been applied under the radiation model to represent the solar insolation or radiation load passing through the transparent Perspex to heat up the air underneath. The amount of radiation is highly depending on the solar insolation available and the value was obtained from solar calculator pre-build in ANSYS Fluent 15. The DO method calculated the direct and diffuse intensity from the sun depending on the location of the plant related to the sun at a specified time and location which could be limited by the user, so there is a solar calculator to specify the directions and solar values.

\subsection{Governing equations}

Various working principle and governing equations have been applied in numerical simulation executed on ANSYS Fluent 15. Conservation of continuity, Momentum and Energy Balance Equations were applied to study the flow field within Swirl Air Generator (SAG) that can be written in tensor form as follows [10]:

Continuity eqn:

$$
\frac{\partial \rho}{\partial t}+\nabla \cdot(\rho \cdot \vec{v})=0
$$

Momentum eqn:

$$
\frac{\partial}{\partial t}(\rho \cdot \vec{v})+\nabla \cdot(\rho \cdot \vec{v} \cdot \vec{v})=-\nabla p+\nabla \cdot\left(\mu\left[(\nabla \vec{v}+\nabla \vec{v} T)-\frac{2}{3} \nabla \cdot \vec{v} I\right]\right)+\rho \vec{g},
$$

In eqn (3), the Boussinesq model was used by setting up the problem with fluid density as a function of temperature.

$$
\begin{gathered}
\left(\rho-\rho_{\circ}\right) g \approx-\rho_{\circ} \beta\left(T-T_{\circ}\right) g \\
(\rho)=\rho_{\circ}(1-\beta \Delta T)
\end{gathered}
$$

eqn (3) is valid when $(1-\beta \Delta T) \ll 1$ 
Turbulence model:

$$
\begin{gathered}
\frac{\partial}{\partial t}(\rho k)+\frac{\partial}{\partial x_{i}}\left(\rho k u_{i}\right)=\frac{\partial}{\partial x_{j}}\left(\alpha_{k} \mu_{e f f} \frac{\partial k}{\partial x_{j}}\right)+G_{k}+G_{b}-\rho \varepsilon-Y_{M} \\
\frac{\partial}{\partial t}(\rho \varepsilon)+\frac{\partial}{\partial x_{i}}\left(\rho \varepsilon u_{i}\right)=\frac{\partial}{\partial x_{j}}\left(\alpha_{\varepsilon} \mu_{e f f} \frac{\partial \varepsilon}{\partial x_{j}}\right)+G_{1 \varepsilon} \frac{\varepsilon}{k}\left(G_{k}+C_{3 \varepsilon} G_{b}\right)-C_{2 \varepsilon} \rho \frac{\varepsilon^{2}}{k}-R_{\varepsilon} .
\end{gathered}
$$

Energy eqn:

$$
\frac{\partial}{\partial t}(\rho \cdot E)+\nabla \cdot(\vec{v}(\rho E+p))=-\nabla \cdot\left(k_{e f f} \nabla T-h \vec{J}+\left(\mu\left[(\nabla \vec{v}+\nabla \vec{v} T)-\frac{2}{3} \nabla \cdot \vec{v} I\right] \cdot \vec{v}\right)\right)+S_{h}
$$

The radiation equation solved by the software can be written as:

$$
\nabla .\left(I_{\lambda}(\vec{r}, \vec{s}) \vec{s}\right)+\left(a_{\lambda}+\sigma_{s}\right) I_{\lambda}(\vec{r}, \vec{s})=a_{\lambda} n^{2} I_{b \lambda}+\frac{\sigma_{s}}{4 \pi} \int_{0}^{4 \pi} I_{\lambda}(\vec{r}, \vec{s}) \varphi\left(\vec{s} . \vec{s}^{\prime}\right) d \Omega^{\prime} .
$$

The solar intensity in each direction $\vec{s}$ and position $\vec{r}$ can be written as follows [10]:

$$
I_{\lambda}(\vec{r}, \vec{s})=\sum_{k} I_{\lambda}(\vec{r}, \vec{s}) \Delta \lambda_{k}
$$

\subsection{Grid independency}

Grid independency was considered in the solution. Five mesh sizes were used, tetrahedral cell sizes ranged between $0.05 \mathrm{~m}$ to $0.005 \mathrm{~m}$ were tested. Logically the use of minimum mesh size resulted in a more accurate solution; however, it increased the run time and overall cost. The mesh size (maximum size $0.01 \mathrm{~m}$ and minimum size $0.001 \mathrm{~m}$ ) was used with the percentage error of $3.2 \%$, and $2.1 \%$ percentage error for velocity and temperature in the preliminary model that is acceptable.

\subsection{Boundary conditions}

The values of the boundary conditions considered as an input parameter in the CFD-simulation were all adopted from the experimental measurements, as given in Table 1. The thermal properties of materials used in the simulation are similar to those in the experimental setup, as in Table 2.

\section{RESULT AND DISCUSSION}

\subsection{Validation of the CFD results}

To validate the numerical assessment, the comparison of the CFD results with the preliminary experimental measurements was made. The outflow swirl updraft was considered as the main parameter for validation. The contour of velocity magnitude distribution of the initial case can be shown in Fig. 5. During the simulations, the average outlet velocity $(1.85 \mathrm{~m} / \mathrm{s})$ was simulated at the centre of the upper hole, and this value is in agreement with the experimental measurement at the same inflow velocity condition $(0.4 \mathrm{~m} / \mathrm{s})$ with the percentage error of $3.2 \%$. While the simulated maximum velocity magnitude was $2.3 \mathrm{~m} / \mathrm{s}$ occurring $20 \mathrm{~cm}$ above the upper hole at both ends of the swirl streams within the USC. 
Table 1: Initial boundary conditions from experimental preliminary model.

\begin{tabular}{|c|c|c|c|}
\hline $\begin{array}{c}\text { Surfaces } \\
\text { components }\end{array}$ & $\begin{array}{c}\text { No. of } \\
\text { items }\end{array}$ & $\begin{array}{c}\text { Boundary } \\
\text { type }\end{array}$ & Boundary conditions \\
\hline $\begin{array}{c}\text { Transparent } \\
\text { structure }\end{array}$ & 1 & Wall & Material: Perspex, T=322.7 K \\
\hline Upper cover & 1 & Wall & Material: Perspex T=322.7 K \\
\hline Upper cover hole & 1 & Outflow & Opening hole, $\mathrm{D}=0.3 \mathrm{~m}$ \\
\hline Inner cylinder & 1 & Wall & Material= Aluminium T=330 K \\
\hline Guide vanes & 8 & Wall & Material $=$ Aluminium T=330 K \\
\hline Air entry slots & 8 & $\begin{array}{c}\text { Velocity- } \\
\text { inlet }\end{array}$ & $\begin{array}{c}\mathrm{V}=0.4 \mathrm{~m} / \mathrm{s} \\
\mathrm{T}=323 \mathrm{~K}\end{array}$ \\
\hline Ambient condition & - & - & $\begin{array}{c}\mathrm{T}=309 \mathrm{~K} \\
\mathrm{~S}=1000 \mathrm{Wm} \mathrm{m}^{2}\end{array}$ \\
\hline
\end{tabular}

Table 2: Thermal properties of materials.

\begin{tabular}{|c|c|c|}
\hline Thermal property & Perspex & Aluminium \\
\hline Properties & $\begin{array}{c}\text { Solid, Semi- } \\
\text { Transparent }\end{array}$ & Solid, Opaque \\
\hline $\begin{array}{c}\text { Thermal } \\
\text { conductivity }(\mathrm{w} . \mathrm{m} / \mathrm{k})\end{array}$ & 0.189 & 202.4 \\
\hline Density $\left(\mathrm{kg} / \mathrm{m}^{3}\right)$ & 1200 & 2719 \\
\hline $\begin{array}{c}\text { Specific heat } \\
(\mathrm{J} / \mathrm{kg} \cdot \mathrm{k})\end{array}$ & 1200 & 871 \\
\hline
\end{tabular}

\subsection{Analyses of swirl updraft flow behaviour}

Simulating the flow behaviour within the SAG \& USC for the initial case is described in Figs 5 and 6 displaying the outflow direction from the vanes as a slope vector along the inflow guide vane height $(30 \mathrm{~cm})$ which moving towards the upper hole. Moreover, a small circulation motion (convection currents) begin to appear at the end of guide height in the bottom corner of the upper cover within the SAG. Also, the figures show the appearance of small vortices at entry slots that are considered as a setback, because they cause a blockage and decline the mass flow rate from the LSC to the SAG body. After the upper hole, the swirl flow structure diverged into two streams and extended into USC with the formation of convection currents around the swirl flow. The reason behind the formation of the convection currents is the contact of the air masses inside the SAG and USC with the hot surfaces (Transparent plates, inner walls).

The flow behaviour after extending the height of the stationary guide vanes and the slot to $60 \mathrm{~cm}$ is shown in Figs 7 and 8. The figures show enhancement in the vortex structure inside SAG due to the increase in the slot area which caused the decay of the circulation motion at the bottom of the transparent corner and decreased the effect of the blockage at the entry slot. As a result, the mass flow rate of the hot air increased in the LSC passing through 


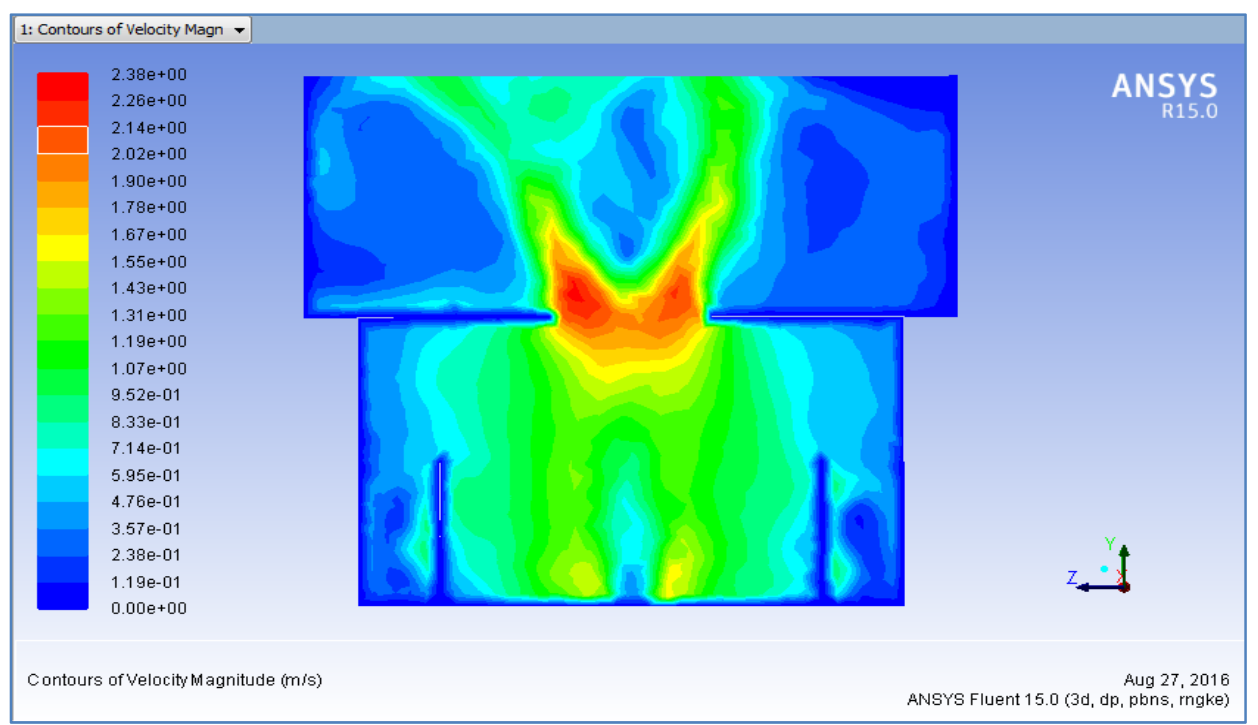

Figure 4: The contour velocity magnitude distribution for the initial case.

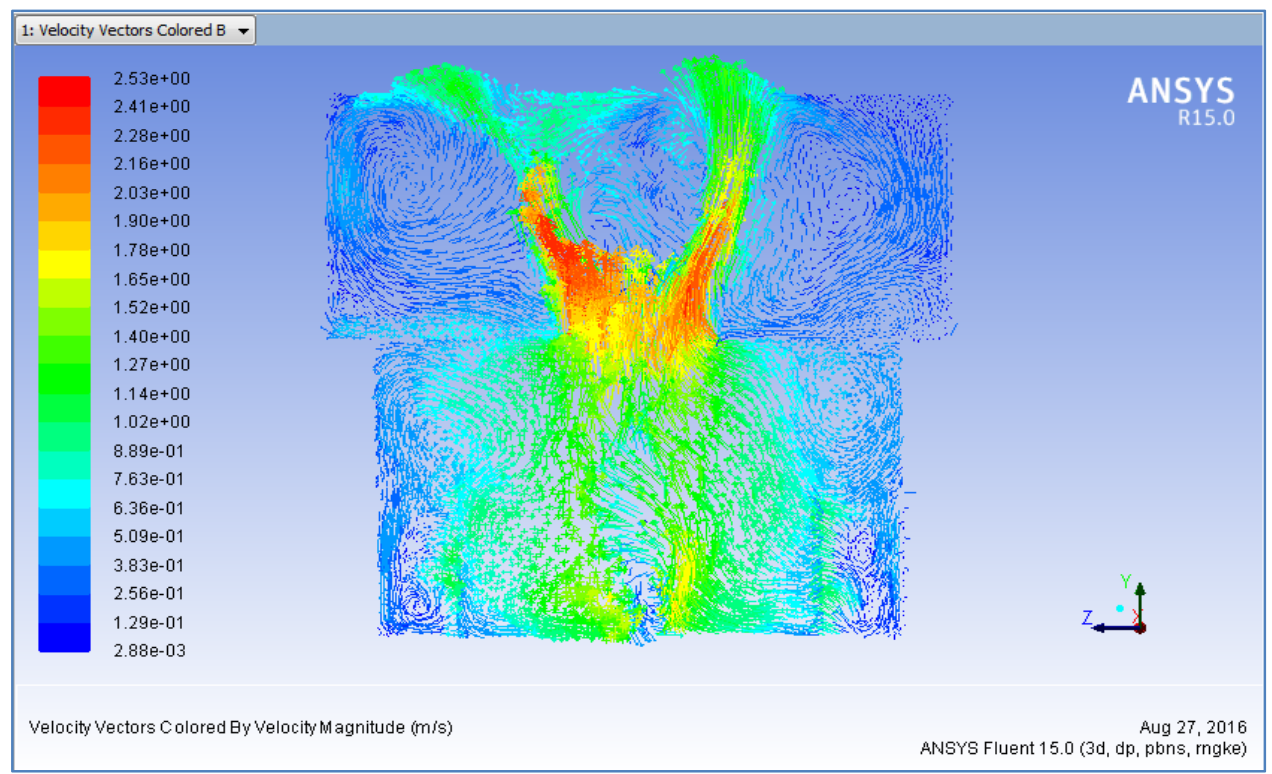

Figure 5: Sectional velocity vectors for SAG \& USC at $30 \mathrm{~cm}$ - inflow guide height. 


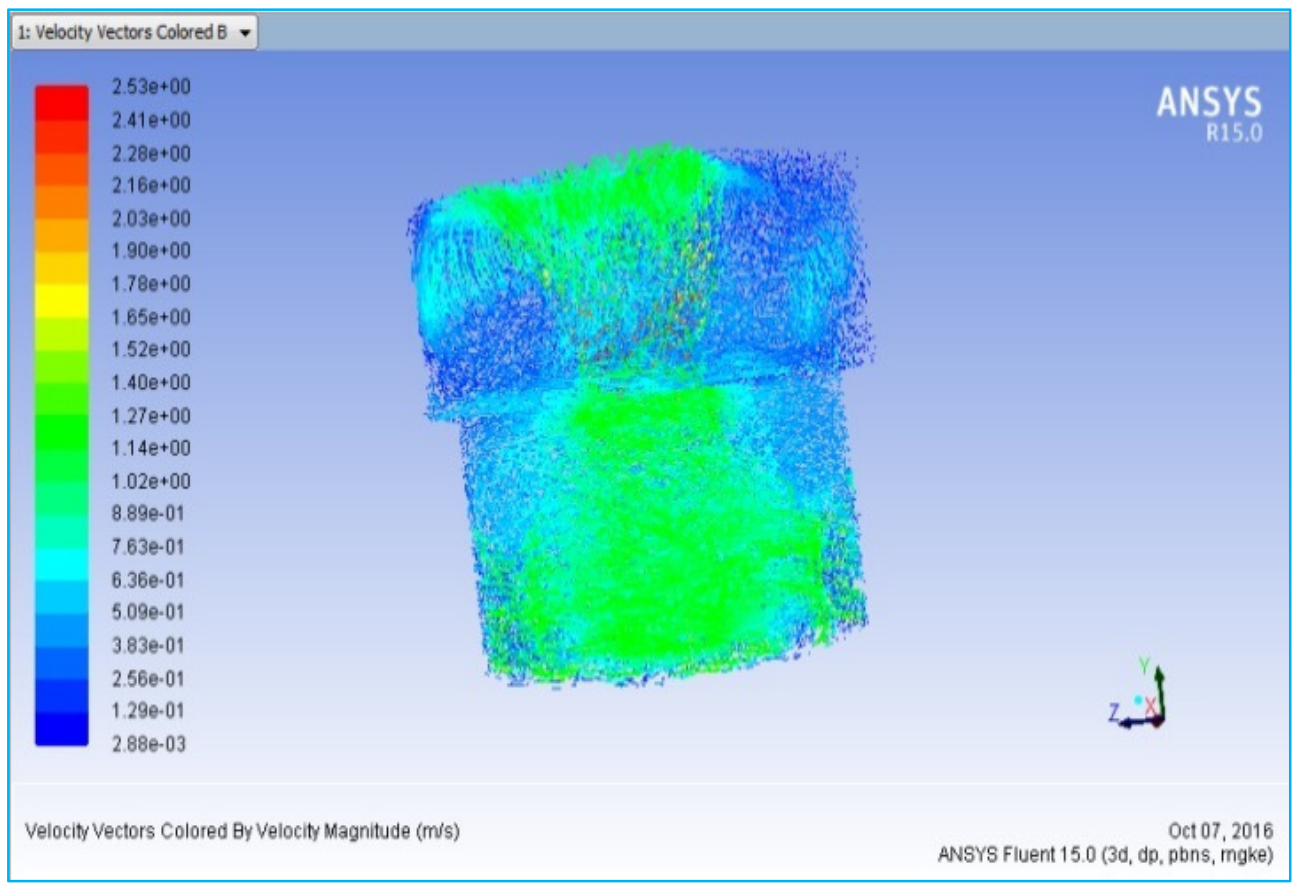

Figure 6: 3D contour velocity vectors for SAG \& USC at $30 \mathrm{~cm}$ - inflow guide height.

the outskirt and inner cylinders of the SAG to enter SAG body with high momentum. In addition, increase in the guide vane height helps to enhance the tangential velocity component and guides all the outlet air flow from the slot to move directly with high vortices same as former swirling towards the upper hole.

Also, it could be clearly observed that the flow structure of the vortex was extended in the USC (Swirl region) without any divergence unlike the initial case. The reason behind this phenomenon is the great momentum of the vortex which reaches the turbulent kinetic energy of $0.073 \mathrm{~m}^{2} / \mathrm{s}^{2}$, simulated in the center of the hole as compared to the primary status i.e. 0.026 $\mathrm{m}^{2} / \mathrm{s}^{2}$ with the same inflow velocity $0.4 \mathrm{~m} / \mathrm{s}$. The enhancement rate at this point has reached $64 \%$.

\subsection{Analyses of the swirl updraft velocity}

The velocity magnitude distribution after extending the inflow guide vanes height to $0.6 \mathrm{~m}$ is shown in Fig. 9. It is clearly observed that there is a significant improvement in the swirl strength emerging from SAG, reaching $3.7 \mathrm{~m} / \mathrm{s}$, simulated in the centre of the upper hole when the inflow velocity was $0.4 \mathrm{~m} / \mathrm{s}$. This shows that the improvement percentage reached $50 \%$ as compared to the inflow guide vane height of $0.3 \mathrm{~m}$. Further, the swirl strength remained almost have the same intensity when the vortex extended within USC corroborating with the role of the inflow guide vanes height as a design parameter. 


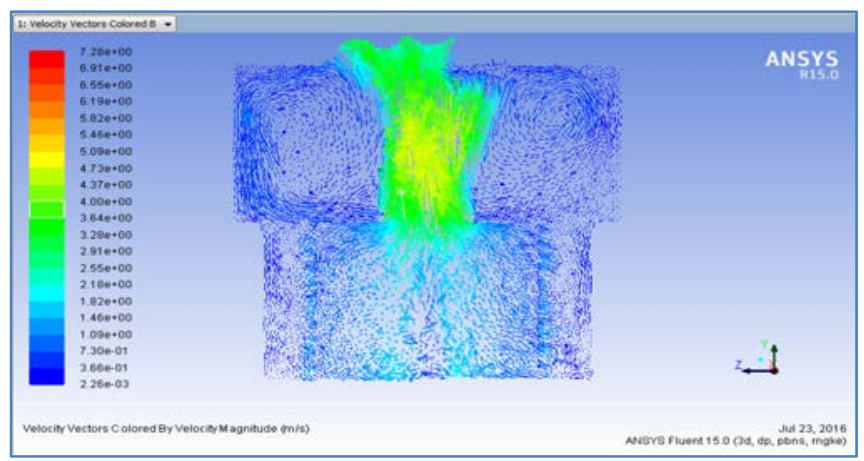

Figure 7: Sectional velocity vectors for SAG \& USC after extended the inflow guide height to $60 \mathrm{~cm}$.

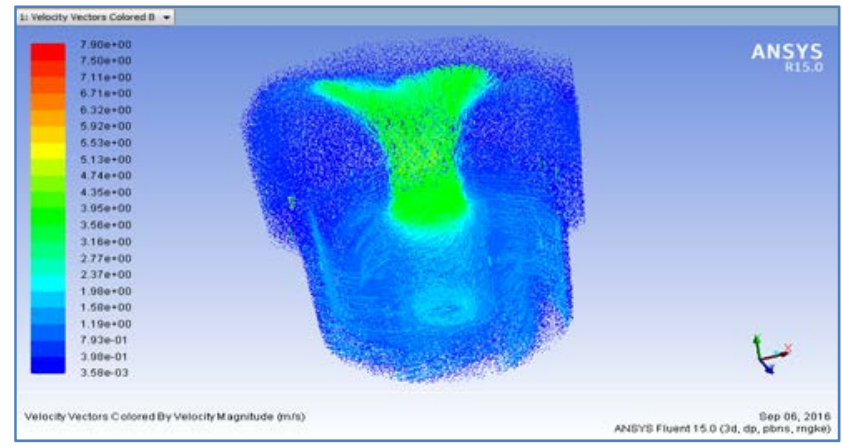

Figure 8: 3D contours velocity vectors for SAG \& USC after extended the inflow guide height to $60 \mathrm{~cm}$.

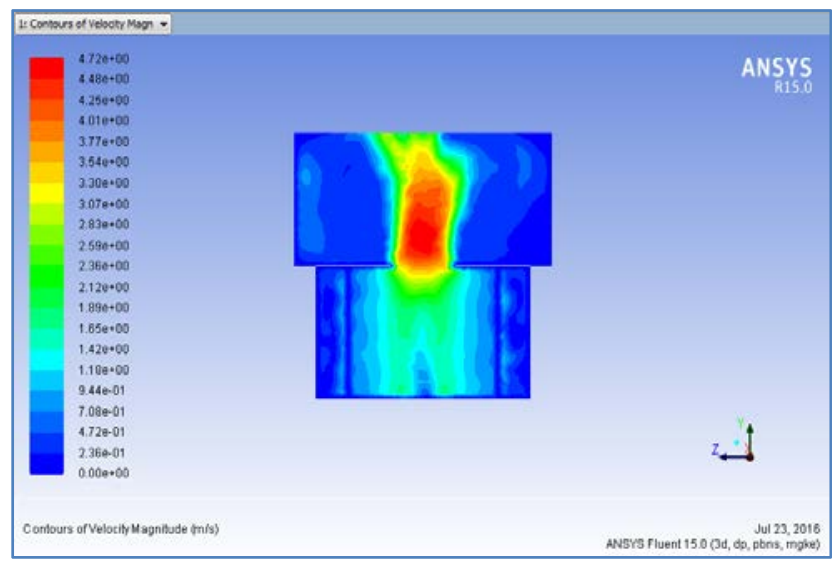

Figure 9: Sectional of velocity magnitude of swirl updraft generated after extended the inflow guide height to $60 \mathrm{~cm}$. 


\section{CONCLUSIONS}

In this paper, modelling of a swirl air generator (SAG) supported by transparent top surface has been simulated computationally by using ANSYS FLUENT 15. SAG is the main part of SVPG model that was proposed as a new arrangement in the solar vortex updraft field for renewable power generation. The impact of inflow guide vanes height on the swirl updraft flow characteristics was investigated and the results were compared with preliminary experimental measurements. For a given geometry of the SAG, the conclusion can be summarised as follows:

1. The CFD results clearly showed that the capability of the new proposed configuration of the SAG for creating the artificial swirl updraft depended on the solar energy.

2. The height of stationary guide vanes is a role design parameter that influences the swirl flow structure and increases the generation of swirl updraft velocity.

3. Increase in the height of the inflow slots results in an increase in the mass flow rate entry to vortex generator and enhances the extract power production.

Based on these results, modification in the existing configuration of the SAG will be used as the second process to modify the SVPG prototype.

\begin{tabular}{|c|c|c|c|}
\hline & \multicolumn{3}{|c|}{6 NOMENCLATURE } \\
\hline $\mathrm{G}_{\mathrm{k}}$ & production of turbulent kinetic energy & & spectral intensity \\
\hline $\mathrm{S}$ & mean rate of strain tensor & $\mathrm{I}_{\mathrm{b} \lambda}$ & $\begin{array}{l}\text { black body } \\
\text { intensity }\end{array}$ \\
\hline $\mathrm{G}_{\mathrm{b}}$ & $\begin{array}{l}\text { generation of turbulence kinetic energy due } \\
\text { to bouency }\end{array}$ & $\alpha_{\lambda}$ & $\begin{array}{l}\text { spectral absorption } \\
\text { coefficient }\end{array}$ \\
\hline $\mathrm{k}$ & kinetic energy & $\mathrm{n}$ & refractive index \\
\hline $\mathrm{C}_{3 \varepsilon}$ & $\begin{array}{l}\text { constant to calculate the degree of } \varepsilon \text { effected } \\
\text { by bouency }\end{array}$ & $\rho$ & density \\
\hline $\mathrm{t}$ & time & $\varepsilon$ & dissipation rate \\
\hline $\mathrm{k}_{\mathrm{eff}}$ & effective conductivity & & \\
\hline $\mathrm{J}_{\mathrm{j}}$ & diffusion flux & & \\
\hline $\mathrm{S}_{\mathrm{h}}$ & heat source due to incident solar radiation & & \\
\hline
\end{tabular}

\section{ACKNOWLEDGEMENT}

The logistic, technical and financial assistance provided by Universiti Teknologi PETRONAS is greatly acknowledged.

\section{REFERENCE}

[1] Nizetic, S., Technical utilization of convective vortices for carbon-free electricity production: a review. Energy, 36(2), pp. 1236-1242, 2011.

[2] Mustafa, A.T., AI-Kayiem, H.H. \& Gilani., S.I.G., A Review of convective and artificial vortices for power generation. International Journal of Sustainable Development and Planning, 10(5), pp. 650-665, 2015.

[3] Michaud, L.M., Heat to work conversion during upward heat convection, Part I: Carnot engine method. Atmospheric Research, 39, pp. 157-78, 1995.

[4] Michaud, L.M., The Atmospheric Vortex Engine ,Ed: Googel, Patent invention no. US7086823 B2, 2006. 
[5] Takhar, H.S. \& Beg, O.A., Mathematical modelling of geophysical vortex flow . International Journal of Fluid Mechanics Research, 32(4), 2005.

[6] Varaksin, A., Romash, M.E. \& Kopeitsev, V.N., Tornado-like vortices generation due to air turbulent convection. Proc. Of the 14th Int . European Turbulence Conf, 1-4 Sep. 2013, France.

[7] AI-Kayiem, H.H. \& Mustafa, A.T., Solar Vortex Engine. Patent invention no PI2015702890, Malaysia, 2015.

[8] AI-Kayiem, H.H. \& Mustafa, A.T. \& Gilani, S.I.G., Vortex field simulation and analysis of a solar updraft power engine. proc. Of the 2nd Int. Conf. On Energy Production and Management (EQ2016), WIT Press: pp 193-202, 2016.

[9] Joel, H.F \& Milovan, P.E., Computational Methods for Fluid Dynamics, $3^{\text {rd }}$ ed., book Publications: Springer, 2002.

[10] ANSYS Fluent Software 15 Help User Guideline. 